\title{
A construção de sólidos geométricos
}

\section{a partir de materiais alternativos}

\section{The construction of geometric solids}

\section{with alternative materials}

\author{
Janio Benevides de Souza Nascimento \\ Colégio Militar Estadual Elza Breves de Carvalho, Boa Vista/RO - Brasil \\ Márcia Jussara Hepp Rehfeldt \\ Centro Universitário Univates, Lageado/RS - Brasil \\ Marli Teresinha Quartieri \\ Centro Universitário Univates, Lageado/RS - Brasil
}

\begin{abstract}
Resumo
O presente trabalho é oriundo de uma dissertação intitulada $O$ estudo da geometria espacial por meio da construção de sólidos com materiais alternativos. Pretende-se descrever os resultados obtidos de um dos objetivos específicos, a saber: construir sólidos geométricos com canudinhos e linha, jujubas e palitos pontiagudos, cartolina, papel-cartão e calcular superfície e volume. Os aportes teóricos estão embasados em autores que sustentam a relevância do estudo da geometria e da construção dos sólidos geométricos. Metodologicamente, trata-se de uma pesquisa qualitativa, na qual a pesquisaação foi utilizada como estratégia para intervenção. Participaram da pesquisa quinze alunos do $2^{\circ}$ ano do ensino médio, de uma escola pública da cidade de Boa Vista, Roraima. A análise dos dados mostrou que os alunos adquiriram habilidade para construir alguns sólidos geométricos e, devido ao uso do material manipulável, compreenderam a relação de Euler e conceitos relacionados à área e volume de sólidos geométricos.
\end{abstract}

Palavras-chave: Sólidos geométricos, Materiais alternativos, Área, Volume, Relação de Euler

\begin{abstract}
This work arises from a Master's thesis entitled The study of spatial geometry by building solids with alternative materials. We intend to describe the results coming from one of the specific objectives, that is: building geometric solids with straws and fishing line, jelly beans and sharp sticks, cardboard, paper board, and then calculate area and volume. The theoretical contributions are grounded in authors who support the importance of studying geometry and also of the construction of geometric solids. Methodologically, it is a qualitative research employing the action research as an intervention strategy. Fifteen 2 nd year high school students from a public school in the city of Boa Vista, Roraima, have participated of the survey. Data analysis has shown that students have acquired the ability to build some geometric solids and have understood the Euler formula and concepts related to the area and volume of geometric solids, due to the use of manipulating materials.
\end{abstract}

Keywords: Geometric solids, Alternative materials, Area, Volume, Euler formula. 


\section{Introdução}

Este estudo foi desenvolvido pelo primeiro autor deste artigo, sob orientação dos demais coautores, em uma escola pública, localizada na zona oeste da cidade de Boa Vista, estado de Roraima, e é resultado parcial da dissertação $O$ estudo da geometria espacial por meio da construção de sólidos com materiais alternativos, desenvolvida no mestrado em Ensino de Ciências Exatas, numa Instituição de Ensino Superior do sul do Brasil. Como se trata de um mestrado profissional, a dissertação desenvolvida abordou um problema real da área de atuação do mestrando. Nesse caso, foi a busca por uma estratégia de ensino que despertasse nos alunos do $2^{\circ}$ ano do ensino médio 0 interesse pela matemática. A prática foi desenvolvida com 15 alunos do $2^{\circ}$ ano do ensino médio de uma escola pública localizada na cidade de Boa Vista, Roraima. Um dos objetivos específicos esteve relacionado à construção de sólidos geométricos com canudinhos e linha, jujubas (balas de goma), palitos pontiagudos (palito de dente), cartolina e papel-cartão, para, posteriormente, calcular superfície e volume. Entende-se que práticas pedagógicas que contemplam a construção dos sólidos geométricos podem auxiliar na compreensão de conceitos como superfícies e volumes.

Assim, no presente artigo, a proposta é discutir alguns resultados obtidos a partir da construção dos sólidos geométricos, trazendo as dificuldades encontradas, os avanços obtidos, bem como as discussões que permearam a prática pedagógica. Para tanto, o estudo está dividido em cinco seções, além das referências bibliográficas que subsidiaram a pesquisa. $\mathrm{Na}$ introdução, é apontada a origem do estudo, o contexto no qual foi ele desenvolvido, a motivação do primeiro autor para implementar a pesquisa, os objetivos desenvolvidos e alguns materiais utilizados. A seção seguinte alguns fundamentos teóricos - aborda parte da fundamentação utilizada para subsidiar o estudo, como Baldissera (2007), Boyer (1996), Freudenthal (1973), Eves (1969), Gerdes (1992), Pavanello (2001), Angeli (2007), entre outros. Na seção três, são descritos os procedimentos metodológicos utilizados, bem como o tipo de pesquisa explorada no decorrer da prática. Já na quarta seção resultados obtidos -, são explanadas algumas atividades realizadas e as respectivas implicações. Por fim, seguem-se as considerações finais e as referências bibliográficas. 


\section{Alguns fundamentos teóricos}

De acordo com Baldissera (2007), a geometria é um ramo da matemática, que estuda as formas planas e espaciais com o auxílio de suas propriedades. Ainda para o mesmo autor, foi a partir da necessidade de constante organização do espaço de terra destinada ao plantio, bem como aos conflitos constantes e inundações frequentes, que se deu origem à palavra geometria que, em grego significa medir terra (geo = terra; metria $=$ medir). Segundo Boyer (1996), Heródoto acreditava que a geometria surgia em virtude da necessidade prática de medir as terras, e Aristóteles entendia que a geometria surgira como uma prática de lazer entre os sacerdotes egípcios. No entanto, de acordo com Aleksandrov (1985), a geometria levou muito tempo para se transformar em teoria matemática.

Para Freudental (1973), a geometria iniciou bem antes de Euclides, ou seja, no momento em que o homem necessitou organizar suas experiências espaciais. De acordo com Eves (1969), foi a partir de observações que o homem passou a perceber as regularidades através de comparações entre as formas existentes na natureza, como a teia de aranha e o contorno circular da lua. Dessa forma, o homem construiu a geometria por intuição, (ou geometria intuitiva), que, posteriormente, tornou-se geometria científica.

Em consonância com os apontamentos de Boyer (1996), Engels (1975) afirma que, devido à necessidade do trabalho do homem, surgiu o "geometrizar", e, como pontua Eves (1969), foi observando as formas geométricas na natureza, que o homem, de forma ativa, reproduziu formas de objetos, tais como: as curvas para as panelas de barro, as retas para as cordas e arcos. O homem fez isso, a fim de satisfazer suas necessidades, sendo então reconhecidas com abstração material.

Em síntese, pode-se inferir que, na visão de Baldissera (2007) e Gerdes (1992), a geometria nasceu como ciência empírica ou experimental, para depois se tornar uma ciência matemática capaz de estabelecer relações entre o desenvolvimento das técnicas de confecções de objetos e antigos meios, despertando, então, o conhecimento geométrico.

Para Gerdes (1992), inicialmente, o homem construiu os objetos e, depois, observou sua regularidade. Ou seja, o homem passou, de forma criativa, a elaborar seus instrumentos, descobrir as vantagens, semelhanças e 
regularidades de determinadas formas. Dessa maneira, passou a construir objetos parecidos com outros, simplificando a reprodução, o que fez crescer o interesse pelas formas, ao ponto de descobrir sua beleza e reproduzi-la em outras situações, além da construção de objetos, nascendo, assim, o conceito de forma.

Segundo Hoffer (1981), o objetivo do estudo da geometria é o desenvolvimento da percepção, tornando o aluno capaz de construir, demonstrar, distinguir e comparar objetos. Também nos Parâmetros Curriculares da Matemática para o Ensino Médio (BRASIL, 2006, p. 75) está expresso:

O estudo da geometria deve possibilitar aos alunos o desenvolvimento da capacidade de resolver problemas práticos do quotidiano, como, por exemplo, orientar-se no espaço, ler mapas, estimar e comparar distâncias percorridas, reconhecer propriedades de formas geométricas básicas, saber usar diferentes unidades de medida. Também é um estudo em que os alunos podem ter uma oportunidade especial, com certeza não a única, de apreciar a faceta da matemática que trata de teoremas e argumentações dedutivas. Esse estudo apresenta dois aspectos - a geometria que leva à trigonometria e a geometria para o cálculo de comprimentos, áreas e volumes.

Porém, o professor, ao decidir pôr em prática tal plano, depara-se com outra realidade, isto é, os alunos pouco conseguem relacionar os conceitos, usar as fórmulas, identificar cada sólido e estabelecer semelhanças. Tal dificuldade é verificada tanto na geometria plana como na geometria espacial, sendo que nessa última, a dificuldade é maior, segundo percepções empíricas dos autores do artigo. Outro agravante é que há professores que, talvez por falta de tempo ou de domínio necessário/suficiente para ensinar esse conhecimento aos alunos, acabam por deixá-la de lado, tratando-a de forma superficial, negligenciando-a. E essa negligência, de acordo com Oliveira (1998), Pirola (1995) e Viana (2000), faz com que os alunos apresentem dificuldades de reconhecer as figuras geométricas planas e espaciais. Os autores sugerem que tal desleixo seja reparado e propõem o desenvolvimento de novas formas de aperfeiçoamento no/do ensino de geometria, tanto plana como espacial. O que se pode notar é que a geometria espacial, muitas vezes, é apresentada aos alunos de forma separada e fragmentada pelos próprios professores, sem o estabelecimento de comparações entre os sólidos. 
Krutetsky (1976) defende que a geometria espacial pode ser aprendida desde que se respeite o desenvolvimento da habilidade de cada aluno, no mesmo espaço de tempo. Para Pires (2000) e Ponte (2003), os professores devem estar cientes de que os conceitos de geometria serão adquiridos pelos alunos a partir de observações, comparações entre figuras vistas de diferentes pontos. Segundo Pavanello (2001, p. 183), "os professores, ao ensinar geometria, pouco se preocupam em trabalhar as relações existentes entre as figuras, fato esse que não auxilia o aluno a progredir para um nível superior na compreensão de conceitos".

No trabalho aqui descrito, o intuito foi analisar a ocorrência de aprendizagem em cálculos de área, bem como a relação de Euler, a partir da construção de triângulos, quadriláteros e hexágonos com canudos e linhas; e, cálculos de volume, a partir da construção de sólidos geométricos com canudos e linha, jujubas e palitos pontiagudos (goma de mascar e palito de dente), cartolina e papel cartão. Nesse contexto, todos os participantes receberam materiais manipulativos a cada atividade.

Para Passos (2006, p. 78), "os materiais manipuláveis são caracterizados pelo envolvimento físico dos alunos numa situação de aprendizagem". De acordo com a autora, tais materiais podem ser objetos usados no cotidiano ou simplesmente "objetos que são usados para representar uma ideia" (PASSOS, 2006, p. 78). Cabe destacar que o potencial do material manipulável depende menos do próprio material e mais da maneira que o docente irá utilizá-lo e das questões que irá formular para levar o aluno a pensar. Em relação a isso, Lorenzato (2006, p. 21) expressa:

[...] convém termos sempre em mente que a realização em si de atividades manipulativas ou visuais não garante a aprendizagem. Para que essa efetivamente aconteça, faz-se necessária também a atividade mental, por parte do aluno. E o MD pode ser um excelente catalisador para o aluno construir seu saber matemático.

Segundo Kaleff (2006), muitos docentes usam materiais manipulativos sem objetivos claros, sem refletir sobre quais conceitos matemáticos poderiam estar representando, apenas consideram as características lúdicas dos materiais, o que não auxilia a aprendizagem do aluno. Portanto, para a autora, é importante que a atividade proposta possibilite ao aluno refletir sobre sua ação, para, assim, construir conhecimentos. Nesse contexto, é recomendável 
que o aluno, de acordo com Lorenzato (2006), além da exploração e reflexão sobre o material didático, também participe da sua construção. Para o autor, o professor poderá garantir que o aluno possa tirar o maior proveito possível desse material manuseado.

De acordo com Kaleff et al (1994, apud COSTA; LIMA 2010, p. 34), deve-se levar materiais mais concretos para as escolas que envolvam a manipulação e também preocupar-se com a elaboração de materiais didáticos que inspire não só a percepção visual, como também a intuição, que aflora no aluno a criatividade individual e o fortalecimento da autonomia e personalidade.

Em relação ao conteúdo de geometria espacial, segundo Kaleff (1995), Santos et al (2013), Dias e Ferreira (2014), a construção de sólidos geométricos pode ser realizada com canudos, barbantes, varetas finas de madeira e elásticos, ou ainda massa de modelar. O aluno poderá construir "esqueletos" de sólidos, e isso, segundo os autores, auxilia na visualização dos sólidos. Para Kaleff (1995, p. 122), “A imagem concreta de sólidos, polígonos e arestas facilita o entendimento e é essencial para o estudo futuro da geometria plana e espacial".

De forma similar, Angeli (2007) comenta que o estudo dos sólidos geométricos requer a visualização e a representação no plano. Sem tais premissas, é praticamente impossível desenvolver qualquer trabalho em geometria. Angeli (2007) sugere ainda que, melhor do que o estudo do espaço, é o estudo da geometria por meio da investigação do "espaço intelectual", já que essa começa com a visão e percepção. Ela vai do que pode ser percebido para o que pode ser concebido, isto é, instiga o aluno a pensar de forma concreta, ou seja, dá forma ao "abstrato". Atividades de caráter geométrico, de acordo com o autor, mudam as atitudes matemáticas dos alunos. Nesse contexto, entende-se que a geometria deveria ser explorada, promovendo atividades que primam pela construção de sólidos e familiarização de conceitos, como aresta, face, vértice, área, volume, entre outros.

\section{Procedimentos metodológicos}

Foi adotada a pesquisa-ação como metodologia para intervenção e desenvolvimento da prática (GIL, 2010). A relevância da pesquisa-ação para este trabalho deve-se ao fato de que ela permite "[...] além de compreender, 
intervir na situação, com vistas a modificá-la. O conhecimento visado articulase a uma finalidade intencional de alteração da situação pesquisada" (SEVERINO, 2008, p. 120), e a análise desses dados se efetivou a partir da discussão em torno dos dados que foram obtidos, de onde decorreu a interpretação dos resultados, conforme Gil (2010).

A pesquisa-ação pode ser entendida como

um tipo de pesquisa em base empírica, que é concebida e realizada em estreita associação com uma ação, ou ainda, com a resolução de um problema coletivo onde todos os pesquisadores e participantes estão envolvidos de modo cooperativo e participativo. (THIOLLENT, 1985, p. 14)

Para Gil (2010, p. 42), a "pesquisa-ação tem características situacionais, já que procura diagnosticar um problema específico numa situação específica, com vistas a alcançar algum resultado prático". Assim, de acordo com os autores citados, neste estudo, a pesquisa-ação foi de fundamental importância para a elaboração de um plano que indicou os objetivos que se pretendeu atingir, o público beneficiado com a pesquisa, assim como os procedimentos que foram adotados para assegurar a participação do público-alvo.

Em relação à análise e interpretação dos dados, na pesquisa-ação, se privilegia a discussão em torno dos dados obtidos, de onde decorre a interpretação dos seus resultados com contribuições teóricas relevantes e também do público participante. Assim, na análise dos dados, foram utilizadas palavras, frases, temas e falas dos alunos, que foram considerados como elementos representativos e que podem ser compreendidos fora do contexto original em que se encontravam. Neste estudo, os alunos foram identificados apenas pelas iniciais dos seus nomes para preservar o anonimato. Para aqueles que têm nomes que começam com a mesma letra, acrescentaram-se um índice numérico para diferenciá-los.

O estabelecimento de ensino em que foi desenvolvida a intervenção pedagógica foi a escola em que o primeiro autor do artigo realiza suas atividades docentes, localizada na zona oeste de Boa Vista-RR. Por localizarse distante do centro da cidade, é discriminada pela distância e pelo histórico de violência.

A escola não possui um laboratório de matemática. Em alguns momentos, as aulas práticas, descritas neste estudo, foram desenvolvidas na 
biblioteca, por ser um ambiente mais apropriado pela existência de mesas grandes, que puderam ser utilizadas por até três alunos simultaneamente, para medir, recortar e colar.

$\mathrm{Na}$ construção dos sólidos, foram utilizados os seguintes materiais: canudinhos, linha, palitos pontiagudos, goma de mascar (jujubas), cartolina e papel-cartão, além dos instrumentos de desenho geométrico, tais como régua, esquadro, compasso e transferidor. Ainda foram utilizados livros didáticos, dicionários, quadro e pincel. No decorrer dessa prática, os alunos efetivaram o cálculo da superfície e volume dos sólidos. As atividades desenvolvidas e o tempo aproximado de duração para realização de cada uma estão apresentadas no Quadro 1 a seguir:

Quadro 1: Cronograma da construção dos sólidos geométricos

\begin{tabular}{|c|c|}
\hline Atividade & № de Aulas $=$ № de encontros \\
\hline $\begin{array}{l}\text { Com } 4 \text { vértices e } 6 \text { arestas, construir um sólido, } \\
\text { no qual de cada vértice partem } 3 \text { arestas, cujas } \\
\text { faces têm a forma de triângulos equiláteros. } \\
\text { Com } 8 \text { vértices e } 12 \text { arestas, construir um sólido, } \\
\text { em que partem } 3 \text { arestas de cada vértice e } \\
\text { possui faces quadrangulares. }\end{array}$ & $1 \mathrm{~h} / \mathrm{a}$ \\
\hline $\begin{array}{l}\text { Com } 6 \text { vértices e } 12 \text { arestas, construir um sólido, } \\
\text { no qual partem } 4 \text { arestas de cada vértice, cujas } \\
\text { faces têm a forma de triângulos equiláteros. }\end{array}$ & $2 \mathrm{~h} / \mathrm{a}$ \\
\hline $\begin{array}{l}\text { Com } 12 \text { vértices e } 30 \text { arestas, construir um } \\
\text { sólido, no qual partem } 5 \text { arestas de cada vértice } \\
\text { e possui faces triangulares. }\end{array}$ & $2 \mathrm{~h} / \mathrm{a}$ \\
\hline $\begin{array}{l}\text { Com } 20 \text { vértices e } 30 \text { arestas, construir um } \\
\text { sólido, no qual partem } 3 \text { arestas de cada vértice, } \\
\text { cujas faces são pentágonos regulares. }\end{array}$ & $1 \mathrm{~h} / \mathrm{a}$ \\
\hline $\begin{array}{l}\text { Construir um prisma de face triangular e de uma } \\
\text { pirâmide de base quadrada. }\end{array}$ & $1 \mathrm{~h} / \mathrm{a}$ \\
\hline $\begin{array}{l}\text { Construir um prisma com } 10 \text { vértices e } 15 \\
\text { arestas. }\end{array}$ & $1 \mathrm{~h} / \mathrm{a}$ \\
\hline Comprovar a Relação de Euler. & $1 \mathrm{~h} / \mathrm{a}$ \\
\hline Construir o cubo com cartolina. & $1 \mathrm{~h} / \mathrm{a}$ \\
\hline Calcular o volume através de cubinhos. & $1 \mathrm{~h} / \mathrm{a}$ \\
\hline $\begin{array}{l}\text { Calcular o volume e a superfície de sólidos em } \\
\text { sala de aula. }\end{array}$ & $2 \mathrm{~h} / \mathrm{a}$ \\
\hline
\end{tabular}

Fonte: Autores da pesquisa, 2015. 
Ao final das construções, eles foram orientados a comparar as construções realizadas com canudinhos, cartolina e papel cartão às embalagens dos produtos de supermercados e as de presentes.

A observação de evidências da aprendizagem foi realizada por meio da análise, durante a construção dos sólidos: tetraedro, hexaedro, octaedro, pirâmide, prisma, cilindro. Observou-se também que os alunos foram capazes de calcular superfície e volume desses sólidos. A seguir, explicita-se, com mais detalhes, cada atividade realizada, em ordem cronológica, bem como os resultados obtidos com a prática.

\section{Análise da construção de alguns sólidos}

Antes de iniciar as atividades envolvendo geometria espacial, foi solicitado aos alunos que procurassem o significado de arestas, vértices e faces. Poucos pesquisaram. Em seguida, em outra aula, solicitou-se que buscassem investigar o que é necessário para ter qualquer um desses três elementos. Só a aluna $\mathbf{S}$, após pesquisar, confirmou que, para ter uma aresta, são necessárias duas faces; para ter um vértice, deve-se ter 3 ou mais arestas; e, para se ter uma face, é necessário ter 3 ou mais arestas.

Então, se propôs aos alunos a seguinte atividade: Com 4 vértices e 6 arestas, construir um sólido, no qual, de cada vértice, partem 3 arestas, cujas faces têm a forma de triângulos equiláteros.

Em seguida, foram entregues 2 canudos para cada aluno, bem como tesoura, régua e linhas. A princípio, questionaram o fato de, com apenas 4 vértices e 6 arestas, terem que fazer sair 3 arestas de cada vértice, isto é, segundo os cálculos deles, dever-se-ia ter disponível 12 arestas, já que 4 vezes 3 arestas resultaria em 12, ou seja, faltariam arestas. Nesse momento, foram indagados: E a pesquisa? Fizeram? Poucos responderam positivamente. Havia sido solicitado que estudassem um pouco sobre as arestas, vértices e faces dos sólidos. Como isso pouco ocorreu, o pesquisador/professor explicou: São 6 arestas, certo? Se vocês têm 2 canudos cada um, então, podem fazer 3 arestas, resultando nas 6 arestas. O que eles não tinham observado inicialmente é que uma aresta é contada 2 vezes, esse era o motivo de resultar em 12 arestas. 
A partir dessa informação, cada aluno, de posse da tesoura e régua, dividiu os canudos em 3 pedaços, obtendo as 6 arestas solicitadas. Após um determinado tempo, todos, com exceção de $\mathbf{S}$ e de $\mathbf{A}$, com as 6 arestas, construíram uma figura com a forma de um hexágono regular. Embora $\mathbf{S}$, no início, tenha tido um pouco de insegurança, com um aceno de cabeça ou um olhar incentivador, prosseguiu na construção e obteve o tetraedro regular. Após o término, solicitou-se que levantasse sua construção, para que os demais vissem. Os que não haviam conseguido realizar a construção ficaram olhando surpresos. Em seguida, todos desmancharam seus hexágonos e rapidamente construíram seus sólidos também.

Solicitou-se, então, que declarassem suas curiosidades, dificuldades, facilidades ou dúvidas no momento da construção. Eis as expressões de alguns alunos:

S - O tetraedro não foi difícil de construir, gastei apenas um pouco do raciocínio, era apenas observar o enunciado. $O$ que achei interessante foi como se formou a figura.

$\mathbf{R}_{\mathbf{2}}$ - Minha dificuldade foi na hora de definir a figura que eu pensava que era um losango, mas, na verdade, era uma pirâmide. Então, tentei fazer uma pirâmide, mas não consegui, não obtive sucesso. E achei interessante o modo de construção da pirâmide, enquanto, no começo, a gente pensa que vai formar um triângulo com volume. Interessei-me muito.

$\mathbf{J}_{1}$ - Bom! A minha dificuldade de construir foi fazer com que o esquema saísse corretamente na hora de colocar a linha dentro do canudo. Eu estava demorando a fazer, mas, no final, consegui fazer o que estava pedindo, que era o tetraedro. O meu erro foi na hora de colocar os seis pedaços de canudo num formato de pirâmide. Só duas alunas, a $\mathbf{S}$ e a $\mathbf{A}$ conseguiram.

$\mathbf{Y}$ - Hoje trabalhamos com arestas e vértices. Construímos uma figura diferente das outras, e bem mais bonita, mas, para se construir essa figura, tem que saber bem o que são arestas e vértices, pois o professor deu só a quantidade de arestas e vértices para fazer a figura com canudos. A dificuldade, eu creio que a partir dessa aula, vai ser maior, mas, daqui para o final do projeto, eu quero aprender bem esse assunto sobre vértices, arestas e face. $O$ interessante é que a forma da figura fica numa forma triangular que consegue se firmar no solo facilmente. 
A Figura 1 ilustra o tetraedro de um dos alunos confeccionado na aula, com canudos e linha.

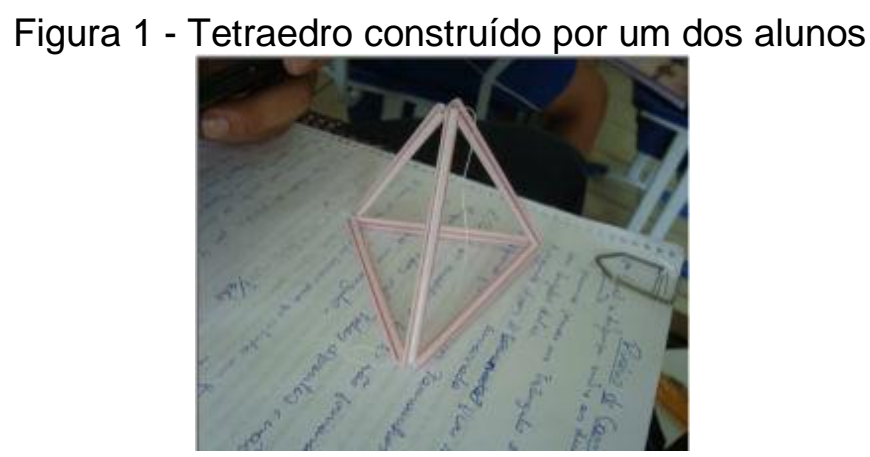

Fonte: Autores da pesquisa, 2015

Embora tenham encontrado dificuldades, todos conseguiram construir seus tetraedros. Apenas uma aluna alegou não ter encontrado dificuldades no momento da construção. O que chamou a atenção nos comentários dos alunos foi o fato de não conseguirem interpretar o enunciado, por exemplo, como "distribuir" tantas arestas em tão poucos vértices. De acordo com Nasser (1998, p. 71):

Os alunos progridem segundo os níveis hierárquicos de conhecimento quando aprendem geometria. Esses níveis podem ser descritos como: reconhecimento (visualização), análise, abstração (síntese) dedução e rigor. Van Hiele estabelece que o progresso de nível depende da experiência de atividades especialmente preparadas pelo professor, com essa finalidade, e passa por cinco fases de aprendizagem. Portanto, o modelo de Van Hiele incorpora ao cognitivo um aspecto didático.

$\mathrm{Na}$ aula seguinte, os alunos foram desafiados com a seguinte atividade:

Com 8 vértices e 12 arestas, construir um sólido, em que partem 3 arestas de cada vértice e possui faces quadrangulares.

Ao distribuir os materiais para cada aluno, deixou-se que tomassem suas iniciativas ou conclusões. O professor foi passando de carteira em carteira, para ver a iniciativa de cada um. Percebeu-se que alguns estudaram em casa qual poderia ser a próxima atividade. Ao visualizarem o enunciado, já foram desenhando nos seus respectivos cadernos o sólido: um hexaedro. Porém, não sabiam o seu nome. Dentre esses valores e atitudes, os PCN's destacam que:

[...] ter iniciativa na busca de informações, demonstrar responsabilidade, ter confiança em suas formas de pensar, fundamentar suas ideias e 
argumentações são essenciais para que o aluno possa aprender, se comunicar, perceber o valor da matemática como bem cultural de leitura e interpretação da realidade. (BRASIL, 2006, p. 45)

Assim, quanto à iniciativa de cortarem os canudos, alguns alunos hesitaram, enquanto outros, de posse da régua, já foram medindo os canudos e cortando. Foram distribuídos três canudos para cada um, além de linha, tesoura e régua. Em pouco tempo, já estavam com o hexaedro quase pronto. $\mathrm{Na}$ Figura 2, apresenta-se um exemplo do hexaedro construído.

Figura 2 - Hexaedro sem as diagonais

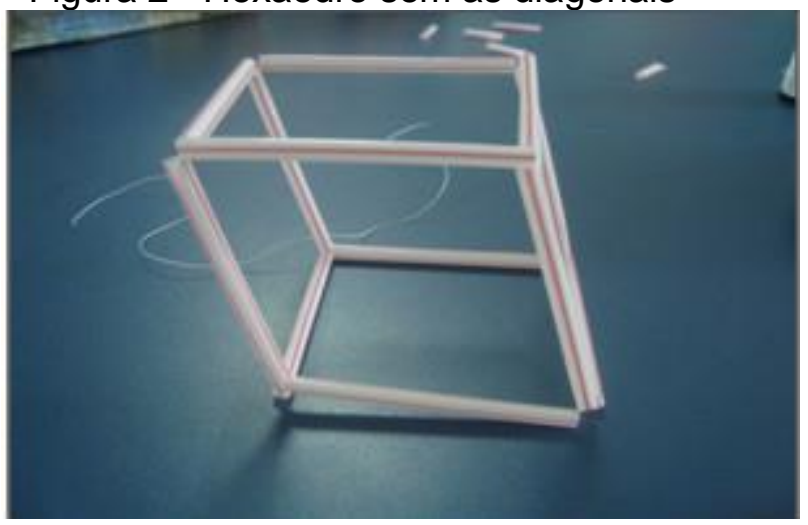

Fonte: Autores da pesquisa, 2015

Observou-se que $\mathbf{E}_{2}$ terminou rapidamente a atividade. Em função disso, ela foi questionada se saberia o que fazer para que o sólido ficasse firme. Ela titubeou, mas, com a ajuda de alguns colegas que ouviram a minha pergunta, respondeu: "Tem que colocar as diagonais em cada face". Os demais colegas continuaram suas construções, e se verificou que alguns alunos enfrentavam dificuldades para amarrar as pontas das linhas. Na Figura 3, o hexaedro construído por um dos alunos que inseriu as diagonais, mesmo assim, não ficou firme como deveria. 
Figura 1 - Hexaedro com as diagonais

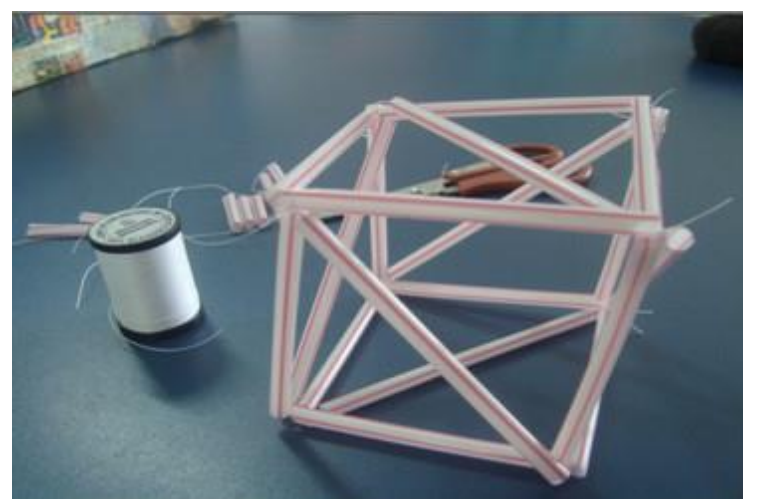

Fonte: Autores da pesquisa, 2015

Ao fim, foi questionado: "Vocês sabem que nome leva esse sólido? Não?". Então, foi sugerido que pesquisassem e, na próxima aula, trouxessem o nome correto. $\mathrm{Na}$ aula seguinte, questionou-se sobre a pesquisa solicitada. Apenas a $\mathbf{S}$ tomou a palavra e disse: "É um hexágono". Questionamos: "hexágono?". Ela, então, repensou e corrigiu. "Ah! Um hexaedro”. E em seguida, completou: "Professor, quando vamos fazer o octaedro e o icosaedro?". Novamente, perguntamos: "O que é o octaedro?". Ela, então, disse que é o sólido que possui 8 faces, e o icosaedro, 20 faces. O professor questionou se ela já tinha visto o dodecaedro, ela disse que não. Ao partir para a construção do octaedro, compreendeu-se que seria melhor utilizar outro material. Esse - as jujubas e palitos - foi sugestão do professor, pois ele havia assistido a um vídeo acerca de uma prática similar ${ }^{1}$. Nesse sentido, como professor, poderia ter proposto aos alunos uma investigação sobre outras possibilidades, diferentemente de como foi realizado. As conjecturas feitas a partir de materiais diversos podem auxiliar no processo de compreensão de construção dos diferentes conceitos (LORENZATO, 2006).

Iniciou-se, então, a construção dos sólidos usando jujubas (utilizadas nos vértices) e palitos pontiagudos (para as arestas). Antes de construir o octaedro, repetiu-se a construção do hexaedro com jujubas, para que eles vissem como a mudança de material influenciaria na aparência do sólido. A Figura 4 mostra o sólido construído.

\footnotetext{
${ }_{1}^{1}$ Disponível em: <http://www.youtube.com/watch?v=ql5agL6LngU>. Acesso em: 20 jan 2012.
} 
Figura 4 - Hexaedro feito com jujubas

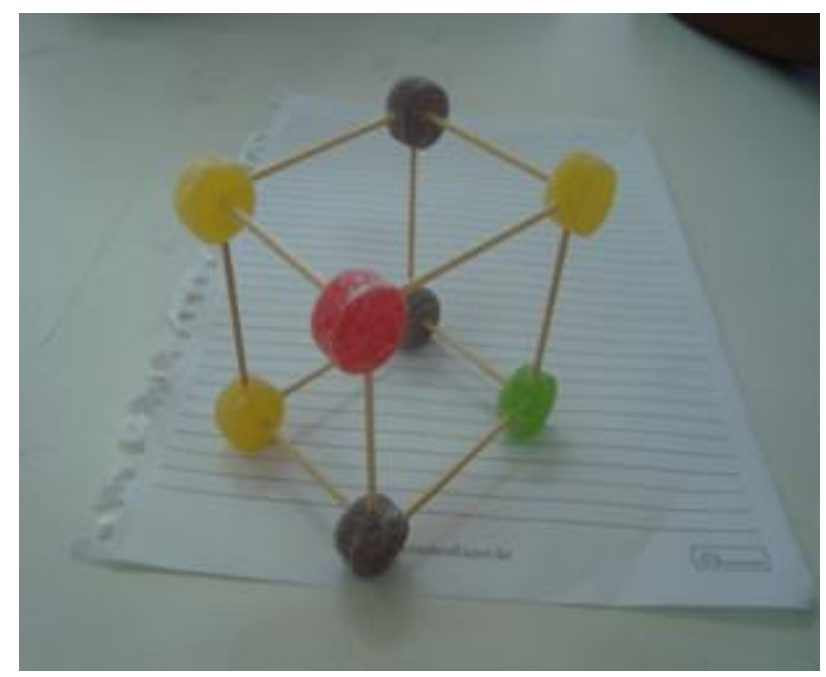

Fonte: Autores da pesquisa, 2015

Em seguida, expôs-se o seguinte enunciado: Com 6 vértices e 12 arestas, construir um sólido, no qual partem 4 arestas de cada vértice, cujas faces têm a forma de triângulos equiláteros. Rapidamente $\mathbf{S}$ terminou de construir o seu octaedro. Novamente, ela revelou haver pesquisado sobre os sólidos, ao ponto de entender como proceder na construção de cada um. Após construir, mostrou aos seus colegas. Nesse sentido, cabe mencionar que a aluna $S$ demonstrou curiosidade e comprometimento com relação ao processo de aprendizagem, não só dela, mas também quando compartilhou seus conhecimentos com os demais alunos. As declarações de $\mathrm{S}$ ao professor confirmaram que ela tinha o hábito de "ler" o livro de matemática, diferentemente dos demais alunos. Cabe ainda destacar que suas atitudes favoreceram a aprendizagem dos conceitos relacionados à construção dos sólidos geométricos de todo grupo de alunos envolvidos na prática pedagógica. 
Na figura 5, o octaedro construído por S:

Figura 5 - Octaedro construído por S

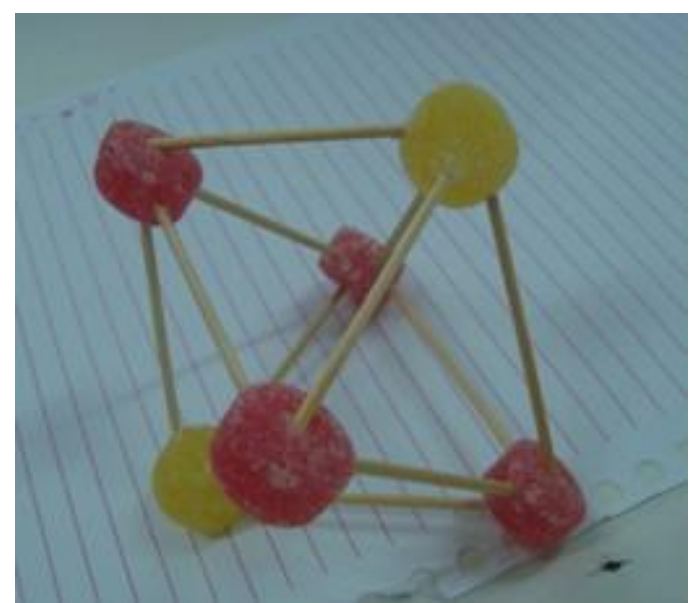

Fonte: Autores da pesquisa, 2015

Outros também estavam terminando suas construções, sem visualizar que $\mathbf{S}$ terminara primeiro. A colaboração demonstrada pelos que iam terminando foi posta em prática, ao ajudar os que estavam com dificuldade. Seguem algumas falas:

S - Achei divertido construir o octaedro com jujubas e palitos. Embora tivesse pesquisado a respeito desse sólido, me compliquei um pouco, mas consegui terminar logo. Percebi que é uma estrutura sólida, mas que se manteria sólida apenas se não comesse as jujubas. Tentação.

J - A aula de hoje, achei melhor, pois o fato de não trabalhar com canudos fez com que o sólido ficasse firme. Interessante. Confesso que tive dificuldade, mas o professor deu uma dica, e então consegui construir 0 octaedro.

$\mathbf{M}_{1}$ - Achei interessante, mas só consegui fazer com o auxílio dos colegas que vieram até minha carteira e me ajudaram.

Percebeu-se que a mudança no material (canudos e linha para jujubas e palitos pontiagudos) ajudou muito na construção, pois ficou mais fácil o manuseio. Todos conseguiram construir seus octaedros, mas, como foi dito, alguns tiveram que ajudar os demais. Todos fotografaram e registraram a aula prática que despertara a curiosidade deles. Algo que os intrigou foi o fato de, em um único vértice, sair mais de 3 arestas. 
A atividade seguinte foi relacionada à construção do icosaedro. Cabe ressaltar que eles ainda não conheciam esse sólido e nem o seu nome. Os dados para a construção foram: Com 12 vértices, e $\mathbf{3 0}$ arestas, construir um sólido, no qual partem 5 arestas de cada vértice e possui faces triangulares.

Lançado o desafio, eles ficaram por um tempo imaginando como poderiam usar tantos palitos (arestas) e apenas 12 jujubas (vértices). Começaram, então, a riscar no papel, a fim de verem como seria essa figura, esse sólido. Porém, apenas a aluna $\mathbf{S}$ conseguiu. $\mathbf{E}$ só após a $\mathbf{S}$ terminar sua construção, os demais deram início às suas construções. No entanto, antes de virem o sólido que $\mathbf{S}$ havia feito, quatro deles tentaram também, porém, a construção que obtiveram foi o prisma de base triangular. Os demais, não obtiveram êxito e produziram outros tipos de sólidos de nome indefinido. Tiveram apenas a preocupação de utilizarem as jujubas e os palitos. Esses ficaram intrigados com o fato de não conseguirem chegar ao objetivo proposto. Após virem o de $\mathbf{S}$, com dificuldade, conseguiram construir os seus também. A Figura 6 mostra o icosaedro construído por um dos alunos, e, em seguida, algumas falas acerca das construções:

Figura 6 - Icosaedro feito por um dos alunos

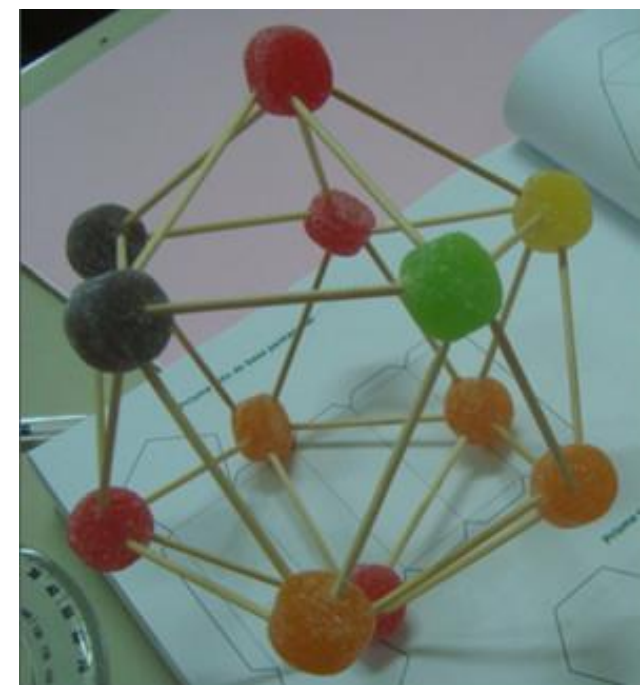

Fonte: Autores da pesquisa, 2015

$\mathbf{A}$ - Tive que contar com a ajuda da $\mathbf{S}$, pois ela terminou primeiro, e, sem a sua ajuda, não teria conseguido. 
$\mathbf{J}_{1}$ - Dessa vez, não consegui sozinho, mas, ao ver que a $\mathbf{S}$ conseguira, então consegui fazer também.

$E_{2}$ - Tive que contar com a ajuda de alguém, e foi o $\mathbf{Y}$ quem me ajudou.

$\mathbf{R}_{\mathbf{2}}$ - Consegui, mas com dificuldade. Claro, o fato de ver a construção da $\mathbf{S}$ ajudou muito mesmo.

Nessa atividade, o fator que predominou foi novamente a colaboração, pois, ao virem que a $\mathbf{S}$ terminara de forma rápida e eficiente, começaram a pedir a ajuda dela, que atendeu aos colegas. De acordo com Dante (2009), ao despertar nos alunos o interesse em algum conteúdo é possível que a participação deles se torne mais efetiva, propiciando maior companheirismo entre eles. Isso também pode colaborar no sentido de um ajudar ao outro na execução e no auxílio em conteúdos novos, gerando entusiasmo ao aprender. Dessa forma, o ensino e a aprendizagem podem ser mais significativos, tornando o trabalho matematicamente mais interessante, e isso pode ser um bom caminho como estratégia metodológica para o ensino dessa disciplina.

$\mathrm{Na}$ aula seguinte, propôs-se o seguinte desafio: com 20 vértices, 30 arestas, construir um sólido, no qual partem 3 arestas de cada vértice, cujas faces são pentágonos regulares.

A construção do dodecaedro, não obteve muita resistência, pois o fato de partir apenas três arestas de cada vértice facilitou a interpretação e construção do sólido. Esse foi o primeiro sólido que todos construíam sem dificuldades, porém, foi realizado em dupla. Percebeu-se que o trabalho em dupla proporciona aos alunos pensar mais, e os resultados obtidos foram positivos. Seguem alguns relatos:

$\mathbf{R}_{1}$ - Bem, essa figura foi mais fácil, pois o fato de partir apenas 3 arestas de cada vértice e possuir faces pentagonais facilitou a construção.

$\mathbf{M}_{\mathbf{2}}$ - Achei que em dupla, a dificuldade foi bem menor, foi mais fácil com a ajuda da colega chegar ao fim da construção.

$\mathbf{M}_{3}$ - Achei espetacular, pois vi que se assemelha com a "esfera". Embora pensasse ser difícil, o fato de construir em dupla tornou mais fácil.

S - Não foi muito difícil montar a figura. O que não gostei foi o fato de, após terminar, as jujubas não suportaram o peso uma das outras e se desmanchou. As arestas eram grandes para que as jujubas suportassem o peso recebido das demais arestas. Precisa de cuidado ao construir. 
O dodecaedro construído por uma dupla de alunos está na Figura 7.

Figura 7- Dodecaedro construído por um dos alunos

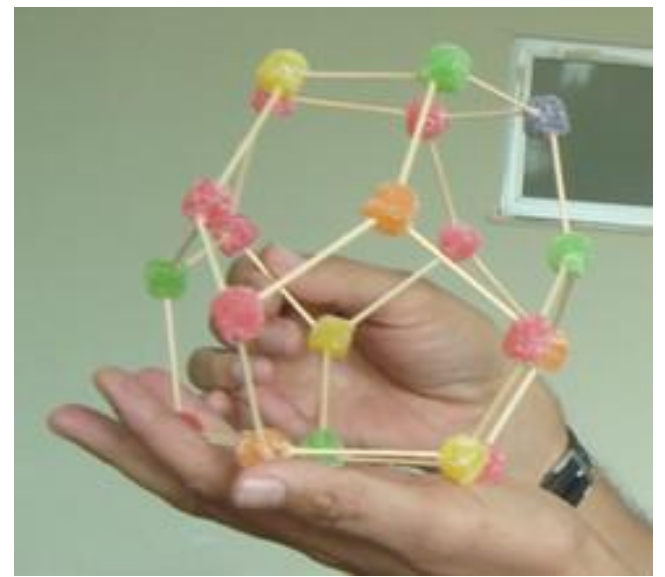

Fonte: Autores da pesquisa, 2015

Analisando os demais comentários, observou-se que todos enfrentaram dificuldades no início, mas, como foi em dupla, um ajudou o outro, e, ao fim, todos conseguiram desenvolver a ideia de construção do dodecaedro. Oliveira (1997, p. 10) afirma que esse desenvolvimento se constitui em um processo de transformação, pois

primeiramente, o indivíduo realiza ações externas que serão interpretadas pelas pessoas ao seu redor, de acordo com os significados culturalmente estabelecidos às suas próprias ações e assim desenvolve os seus processos psicológicos internos.

A atividade seguinte foi mais fácil, pois os sólidos possuíam menos arestas e menos vértices, o que facilitou a compreensão de quase todos. Trata-se da construção de um prisma de face triangular, de uma pirâmide de base quadrada e, por fim, um prisma de base pentagonal.

Ao expor os dados no quadro, omitiu-se a informação de quantas arestas partiam de cada vértice. $\mathrm{O}$ aluno $\mathbf{Y}$ prontamente se manifestou: "Professor, não vai dizer a quantidade de arestas que partem de cada vértice?". Percebeu-se que essa informação ajudara em muito nas aulas anteriores. Então, foi respondido para ele e para os demais que esperavam uma resposta que seria útil a todos: "Hoje, a aula é com um grau maior de dificuldade, logo vocês precisam prensar mais". 
Mesmo com essa omissão, em tempo recorde, eles terminaram suas construções. A pirâmide foi feita primeiro e de forma mais fácil. Em relação ao prisma, ocorreram dificuldades. Alguns não sabiam o que era um prisma, mas, mesmo assim, tentaram construir. $\mathbf{A}$ aluna $\mathbf{E}_{2}$ disse que estava fazendo a pirâmide, mas, na verdade, estava construindo o prisma. Ao terminar, perguntou-se a ela se o que terminara de fazer era uma pirâmide, ela respondeu que não. Começou a segunda construção, fazendo a pirâmide.

Na Figura 8, temos o prisma de base triangular e a pirâmide de base quadrangular.

Figura 8 - Pirâmide de base quadrangular e o Prisma de base triangular

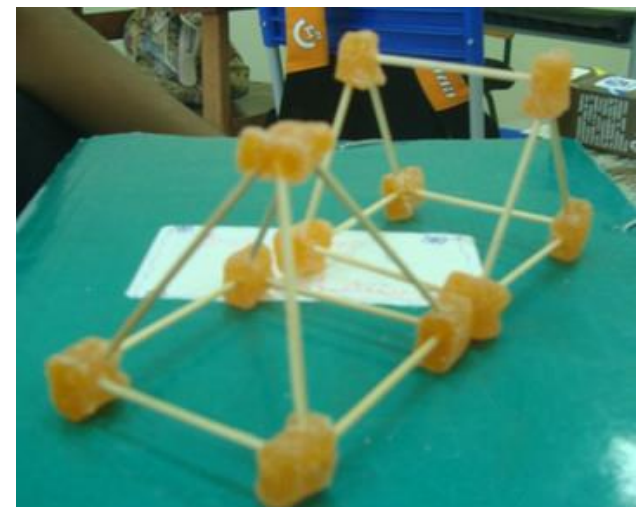

Fonte: Autores da pesquisa, 2015

Após esse desafio, os alunos foram instigados a construir o prisma de base pentagonal. Cabe ressaltar que essa construção foi mais fácil, uma vez que já haviam construído o prisma de base triangular. As dúvidas estavam alicerçadas na forma da base do prisma. No entanto, com o auxílio do professor, conseguiram construir o sólido como mostra a Figura 9.

Figura 9 - Prisma de base pentagonal

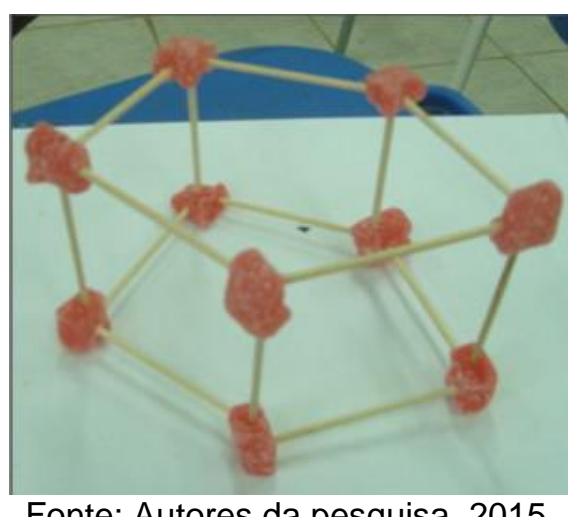

Fonte: Autores da pesquisa, 2015 
Em adição, salienta-se que a construção de figuras geométricas planas (triângulos, quadrados, entre outros) foi desenvolvida anteriormente aos estudos com os sólidos geométricos, haja vista que os alunos necessitavam desses conhecimentos prévios, conforme apontou um estudo realizado preliminarmente.

Com relação aos comentários realizados após as três construções, citam-se os a seguir:

Y - A pirâmide foi fácil pelo fato de se tratar de poucos vértices e poucas arestas. Já o prisma, por não saber como era a sua forma, foi difícil no início, mas, como a base era triangular, logo visualizei que os vértices se encontravam nas bases, e então foi fácil usar as arestas que restavam. Já o prisma de base pentagonal foi mais fácil, pois segui o modelo do primeiro. Se o prisma de base triangular tinha como base um triângulo, logo o prisma de base pentagonal, tinha como base um pentágono.

S - A pirâmide foi fácil. Não tive dificuldade de manejar as jujubas e os palitos, mas o prisma de base triangular me enrolou. Meu raciocínio ficou lento. Achei difícil a construção, e o prisma de base pentagonal foi mais fácil, pois já havia feito o de base triangular.

$J_{3}$ - Achei mais fácil que os demais. Eles são pequenos e práticos. Os outros eram grandes e complicados.

Ao analisar as falas dos alunos, as considerações suscitaram o que está expresso nos PCN's:

[...] os alunos, confrontados com situações-problema, novas, mas compatíveis com os instrumentos que já possuem ou que possam adquirir no processo, aprendem a desenvolver estratégia de enfrentamento, planejando etapas, estabelecendo relações, verificando regularidades, fazendo uso dos próprios erros cometidos para buscar novas alternativas; adquirem espírito de pesquisa, aprendendo a consultar, a experimentar, a organizar dados, a sistematizar resultados, a validar soluções; desenvolvem sua capacidade de raciocínio, adquirem autoconfiança e sentido de responsabilidade; e, finalmente, ampliam sua autonomia e capacidade de comunicação e de argumentação. (BRASIL, 2006, p. 52)

Na mesma aula em que foi construído o prisma de base pentagonal, foi lançado um novo desafio: Construir um prisma com 10 vértices e 15 arestas. $O$ detalhe é que não foi informado o formato da base. Apenas foi dito que observassem a construção do prisma de base triangular e que, de lá, retirassem informações válidas para todos os prismas: todo prisma, 
independente da classificação, possui bases paralelas. Os alunos $\mathbf{J}_{\mathbf{1}}, \mathbf{M}_{\mathbf{3}}$ e $\mathbf{E}_{\mathbf{2}}$ construíram-no de forma regular, no que diz respeito às bases. Os demais conseguiram, após visualizarem as construções dos três colegas citados, porém, não atentaram para a regularidade das bases e fizeram uma espécie de "casinha".

De forma contrária a como vinha se posicionando anteriormente, a $\mathbf{S}$ foi a única que enfrentou dificuldade para construir o seu prisma; mesmo depois que os colegas já haviam terminado, ela se negou a olhar as construções deles. Depois de algum tempo, terminou. Ao fim, a $\mathbf{M}_{2}$ e $\mathbf{E}_{2}$ uniram as bases dos seus prismas, como mostra a Figura 10.

Figura 10 - Junção de 2 prismas de base pentagonal

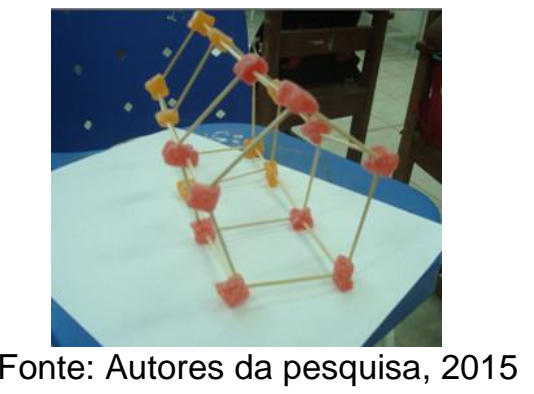

Indagou-se os alunos a seguinte questão: Quantos vértices e quantas arestas possuem esse novo sólido? Os demais alunos que observavam 0 questionamento, prontamente tomaram a palavra e disseram: 20 arestas e 30 vértices. Percebeu-se, então, que não assimilaram a ideia de prismas.

Pode-se intuir, de acordo com Teixeira (2009), que há um distanciamento entre a matemática intuitiva e a simbólica, resultado do caráter abstrato do ensino. Ainda segundo o mesmo autor, na maioria das vezes, a matemática parte do abstrato, e não de situações concretas, e isso pode causar um desconforto, pois essa habilidade (abstração) não é fácil de visualizar e aplicar na vida diária, que, normalmente, exige soluções práticas e imediatas para problemas. Nesse momento, eles foram informados de que todos os prismas têm a mesma propriedade: bases paralelas da mesma forma e as faces laterais têm a forma retangular. Entretanto, ao unirem dois prismas pelas bases, a nova figura continua com o mesmo número de arestas e vértices como foi demonstrado na Figura 10. 
Analisando os comentários dos alunos, notou-se que a maioria deles, ou seja, 10 alunos, não tiveram muita dificuldade em construir a pirâmide e 0 prisma. Esses alunos alegaram que o fato de ter poucas arestas e poucos vértices facilitou a construção. Ao final da aula, foi explanado um pouco sobre os prismas e suas propriedades, destacando que todo prisma possui um par de bases paralelas e as faces laterais têm o formato retangular.

Sugeriu-se, então, que pesquisassem a razão de os sólidos platônicos receberem esses nomes, bem como por que os demais, como a pirâmide de base quadrada, pentagonal, os prismas de base triangular, pentagonal entre outros, não serem classificados como sólidos platônicos. Apenas a $\mathbf{E}_{2}$ e a $\mathbf{M}_{2}$ utilizaram o livro de matemática para verificaram essa informação.

Os sólidos platônicos são poliedros, em que todas as faces são polígonos regulares geometricamente iguais e em cada vértice se encontra 0 mesmo número de arestas. Assim, existem apenas cinco sólidos platônicos: 0 tetraedro, o cubo, o octaedro, dodecaedro e o icosaedro.

Ao fim, expôs-se a tabela com o nome de cada poliedro construído e se solicitou que completassem com o número de vértices, arestas e faces, com o objetivo de que os alunos chegassem à Relação de Euler. Com o auxílio deles, foi preenchida a primeira linha. As demais, cada aluno preencheu e, em seguida, discutimos a Relação de Euler presente no número de vértices, arestas e faces. Para o preenchimento, eles utilizaram o caderno de campo, bem como as anotações feitas durante as construções. Na Tabela 2, tem-se a Relação de Euler.

Tabela 2: Comprovação da Relação de Euler

\begin{tabular}{l|c|c|c|c}
\hline & Vértices & Faces & Arestas & $\boldsymbol{V}+\boldsymbol{F}-\boldsymbol{A}=\mathbf{2}$ \\
\hline Tetraedro & 4 & 4 & 6 & $4+4-6=2$ \\
Hexaedro & 8 & 6 & 12 & $8+6-12=2$ \\
Octaedro & 6 & 8 & 12 & $6+8-12=2$ \\
Dodecaedro & 20 & 12 & 30 & $20+12-30=$ \\
& 12 & 20 & 30 & $12+20-30=$ \\
Icosaedro & 5 & 5 & 8 & 2 \\
Pirâmide & 6 & 5 & 9 & $6+5-8=2$ \\
Quadrangular & 10 & 7 & 15 & $10+7-15=2$ \\
Prisma triangular & & &
\end{tabular}

Fonte: Autores da pesquisa, 2015 
A maioria dos alunos notou a relação entre os elementos do sólido. É sabido que os conhecimentos geométricos constituem parte importante e indispensável do currículo de matemática no ensino médio. Os Parâmetros Curriculares Nacionais destacam, dentre outras coisas, a importância desses conhecimentos na formação dos alunos:

Os conceitos geométricos constituem parte importante do currículo de matemática no ensino fundamental, porque, por meio deles, o aluno desenvolve um tipo especial de pensamento que the permite compreender, descrever e representar, de forma organizada, o mundo em que vive. $O$ trabalho com noções geométricas contribui para a aprendizagem de números e medidas, pois estimula a criança a observar, perceber semelhanças e diferenças, identificar regularidades e vice-versa. (BRASIL, 1997, p. 56)

Entende-se que os conhecimentos prévios acerca de conceitos geométricos devem ser desenvolvidos no ensino fundamental, para que o aluno compreenda a noção de espaço. No entanto, quando isso não ocorre, como indicou o estudo preliminar, é recomendado que se desenvolvam práticas pedagógicas, no sentido de suprir as lacunas de aprendizagem.

Após a comprovação da fórmula de Euler, foi desenvolvida a construção do cubo com cartolina, com o seguinte enunciado: Construir um cubo de $\mathbf{5 c m}$ de aresta. Todos, sem exceção, compreenderam e deram início à construção do cubo. Porém, apenas 3 alunos $\left(\mathbf{S}, \mathbf{M}_{3}, \mathbf{Y}\right)$ usaram o esquadro $\mathrm{e}$ a régua para suas marcações; os demais usaram só a régua. Durante a atividade, observou-se que os alunos conseguiram realizar a construção do cubo, embora alguns não tenham atentado para as abas. A Figura 11 apresenta o cubo feito com cartolina.

Figura 11 - O cubo construído com cartolina

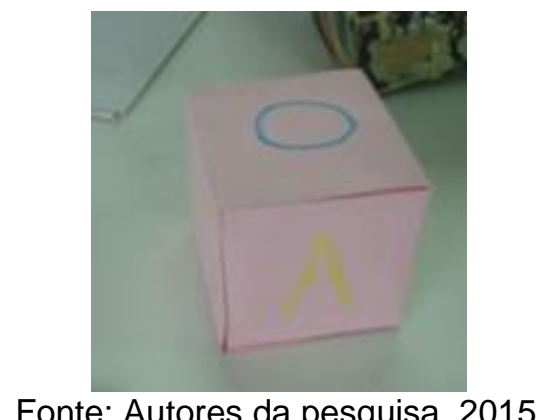

Repetiu-se, então, a atividade, dessa vez, com arestas de tamanhos diferentes, pois a finalidade era enchê-los com cubinhos feitos manualmente 
em casa, semelhantes ao material dourado. Depois de concluída a construção do cubo com cartolina, foram apresentados a eles os cubinhos de madeira, uma versão artesanal do material dourado que fizeram em casa, para que pudessem visualizar e calcular o volume dos cubos que eles construíram. Com isso, foi calculada a área da base, ou de cada face, e o volume da cada sólido. No entanto, os cubinhos fabricados em casa não eram perfeitos, ao ponto de suas dimensões serem exatas, e aconteceu o seguinte: no cubo construído com cartolina cuja aresta era $6 \mathrm{~cm}$, couberam 5 cubinhos de madeira na aresta da base, resultando em 25 cubinhos na área da base. No cubo construído com cartolina, cuja aresta era $7 \mathrm{~cm}$, couberam 6 cubinhos de madeira na aresta da base, resultando 36 cubinhos na área da base. No cubo construído com cartolina cuja aresta era $10 \mathrm{~cm}$, couberam 9 cubinhos de madeira na aresta da base, resultando em 81 cubinhos na área da base.

Essas "falhas" foram notadas no momento em que preenchiam as caixas recém-construídas, pois, nas faces das bases, não coube o número esperado, isto é, o $1^{\circ}$ cubo de aresta $6 \mathrm{~cm}$ era para comportar em sua base 36 cubinhos, 0 2 ํㅡㄹ cubo de aresta $7 \mathrm{~cm}$ era para comportar 49 cubinhos em sua base, e o cubo de aresta $10 \mathrm{~cm}$ era para comportar 100 cubinhos em sua base. Na Figura 12, pode-se observar duas construções em que comprovaram a falha advinda do material utilizado: no cubo de aresta $\mathbf{a}=6$, o da esquerda, couberam 125 cubinhos ao invés de 216, e no cubo de $\mathbf{a}=\mathbf{7}$, o da direita, couberam 216 cubinhos ao invés de 343, como mostra Figura 12.

Figura 12 - Cubos de arestas $6 \mathrm{~cm}$ e $7 \mathrm{~cm}$, respectivamente

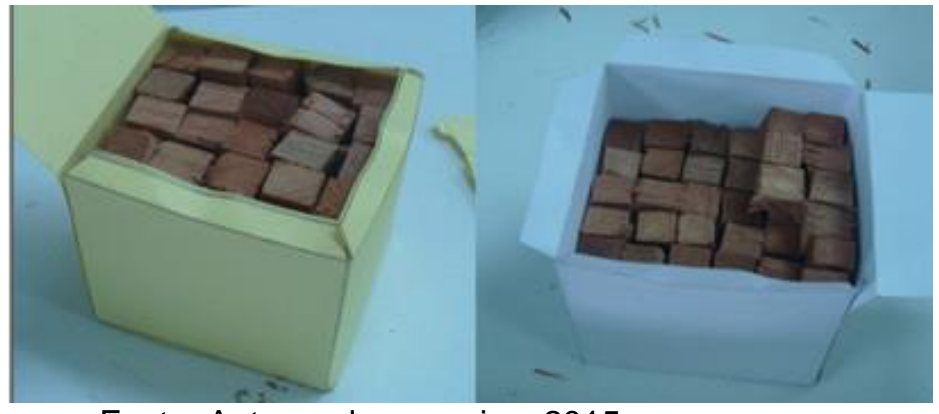

Fonte: Autores da pesquisa, 2015

A partir das "falhas", ocorreram discussões e problematizações acerca do cálculo do volume. Os alunos perceberam tais falhas, mas conseguiram compreender que o volume de um cubo é calculado como sendo $V=a^{3}$. 
Em seguida, foram distribuídos 50 cubinhos para cada aluno e foi sugerido que fizessem blocos, ou que os empilhassem, para que pudessem visualizar as três dimensões. Perguntou-se qual era o volume de cada bloco construído. Todos deram respostas diferentes, em virtude da quantidade de cubinhos utilizados, como mostra a Figura 13.

Figura 13 - Percepção do volume do cubo e de dois paralelepípedos

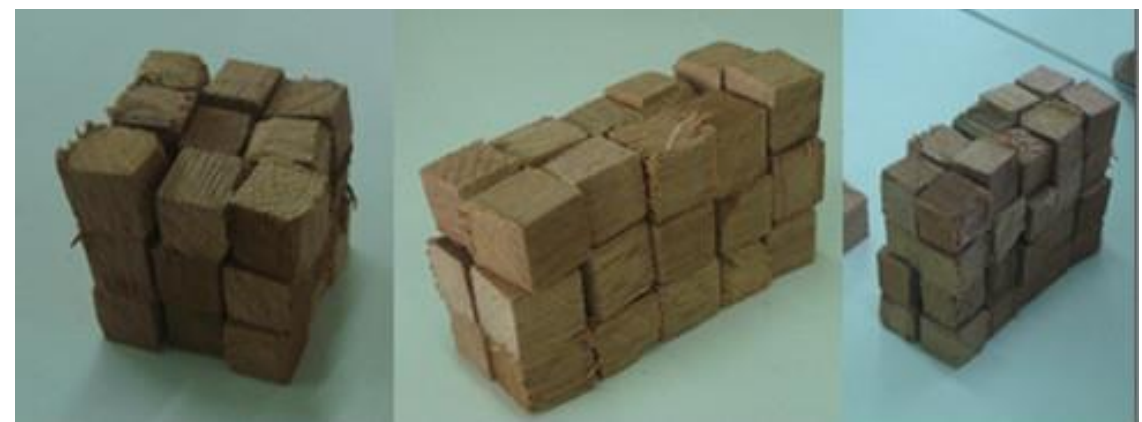

Fonte: Autores da pesquisa, 2013.

O objetivo desta atividade foi instigar os alunos a perceberem que, em qualquer sólido cujos ângulos são retos e suas bases quadrangulares (caso do cubo e do prisma de base quadrada) e base retangular (caso do paralelepípedo), o volume pode ser calculado, multiplicando-se as três dimensões, isto é, $\mathbf{V}=\mathbf{a}$.b.c. Além disso, tinha o intuito de que percebessem que, independente da ordem que contassem os cubinhos empilhados, 0 resultado seria sempre o mesmo.

O uso dos cubinhos semelhantes ao material dourado teve o objetivo, não apenas de proporcionar a visualização das propriedades, características e formação dos prismas, mas também de produzir objetos utilitários, relacionando, dessa forma, o conteúdo aprendido com sua aplicação em situações reais. O cálculo de volume com a utilização do material dourado teve também como objetivo o desenvolvimento da interpretação e da percepção espacial. De acordo com Alsina, Burguês e Fortuny (1988, p. 16, tradução nossa):

A percepção espacial pode ser comparada com a interpretação de um texto escrito. Da mesma forma que, no processo de leitura, são agrupadas as palavras em frases para a obtenção de um entendimento global da informação, na percepção espacial, trata-se de obter uma mensagem através de uma interpretação e visualização das formas e relações das propriedades geométricas espaciais. 
Ainda segundo esses autores, os níveis de organização espacial devem partir da construção de atividades. O conceito geométrico de espaço não é dado, mas construído mentalmente, depois de fazer operações adequadas. Cabe frisar que a percepção de espaço não é uma simples cópia da realidade, mas o resultado de atividades organizacionais e de codificação de informações sensoriais.

$\mathrm{Na}$ aula seguinte, foi distribuída novamente uma mão cheia de cubinhos para cada aluno e se solicitou que os organizassem lado a lado, como se fossem ladrilhar uma superfície qualquer. Nessa aula, o ideal seria se tivéssemos, ao invés de cubos de madeira, pedaços quadrados de tábuas cuja espessura fosse a menor possível e cuja área medisse $1 \mathrm{~cm}^{2}$, para, então, demonstrarmos o cálculo da área. Nesse momento, foi solicitado que desprezassem 0 volume dos cubinhos e considerassem apenas uma das faces, para que pudessem visualizar a área quadrada ou retangular como sendo o produto de duas dimensões: largura $X$ comprimento. Alguns formaram áreas quadradas, outros, áreas retangulares, outros enfileiraram os cubinhos. $\mathrm{Na}$ Figura 14, temos as áreas construídas e calculadas por eles com a utilização dos cubinhos feitos na marcenaria.

Figura 24 - Cálculo da área de superfícies planas

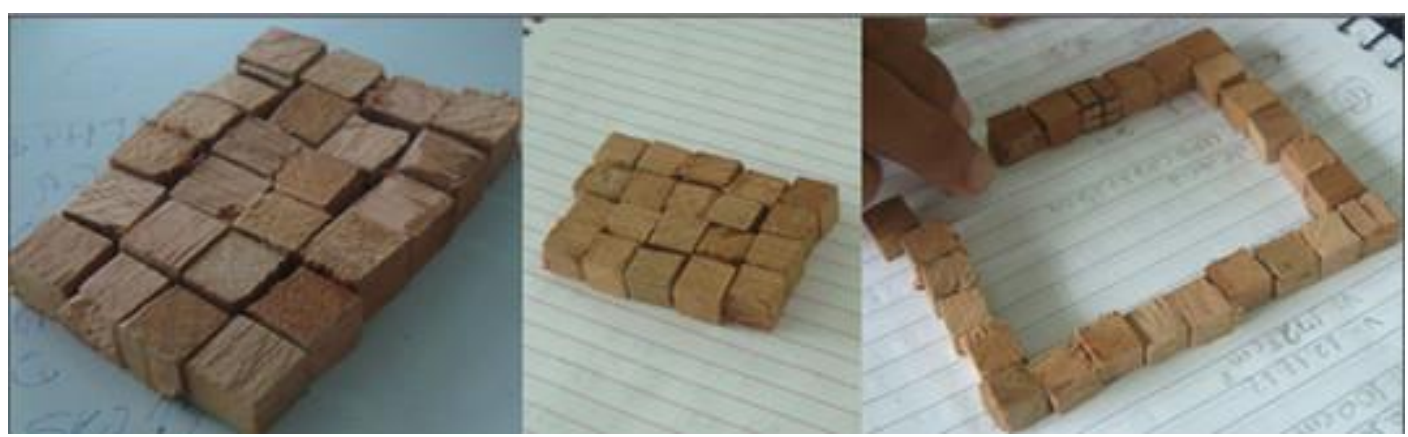

Fonte: Autores da pesquisa, 2013.

Foi solicitado que calculassem a área ocupada pelos cubinhos no plano, ou seja, sobre a sua carteira/classe. Novamente, alguns contaram um a um, enquanto outros foram mais rápidos, multiplicando as duas dimensões: largura e comprimento. $O$ objetivo dessa aula era alcançar o entendimento de todos de que a área é o produto entre a largura e o comprimento de qualquer figura plana, quadrilátera, cujos ângulos internos sejam (são) retos. 


\section{Considerações finais}

Ao terminar este estudo, percebeu-se que construir é mais interessante do que apenas ler, interpretar e calcular. Presenciou-se 0 interesse e 0 entusiasmo em cada aluno, quando era anunciado que, naquele dia, naquela tarde, teríamos uma aula diferente. Eles aguardavam cada aula prática, pois, pela primeira vez, estavam construindo algo real e prático, segundo menções feitas pelos próprios alunos.

Observou-se o quão relevante é deixar os alunos errar, acertar, perguntar, experimentar, debater e trabalhar colaborativamente. Também se verificou que práticas como essa exigem paciência e despreocupação com 0 tempo para aprender.

No decorrer do desenvolvimento da prática pedagógica, observou-se a contribuição do uso de materiais alternativos nos processos de ensino e de aprendizagem da geometria espacial. Ao decidir pela construção dos sólidos com materiais alternativos, levou-se em conta a aquisição desses, por serem de baixo custo, o que torna acessível a quem queira desenvolver essa prática, contribuindo para a aprendizagem de geometria espacial. Ainda entende-se, assim como Kaleff et al (1994), que, na geometria espacial, os alunos ficam, muitas vezes, presos a fórmulas, o que pouco contribui para a identificação de elementos, bem como para o estabelecimento de relações entre eles.

Quanto ao objetivo proposto, esta investigação obteve êxito. A construção dos sólidos geométricos com canudinhos e linha, posteriormente, jujubas (goma de mascar) e palitos pontiagudos (de dente) e finalizando com cartolina e papel-cartão favoreceu o cálculo de superfície e volume dos sólidos construídos. Cada ação praticada pelos alunos se centrou em torno do concreto, de algo que estava em suas mãos e diante dos seus olhos. Observou-se que os alunos desenvolveram o interesse por esse tema, pois perceberam que existem sólidos geométricos presentes em muitas situações do cotidiano.

Ao finalizar este trabalho, acredita-se que os resultados encontrados com a investigação poderão ser direcionados a todos os profissionais da educação, em especial, aos professores de matemática, que reconhecem que, por meio da geometria, pode-se auxiliar o educando a construir uma base de 
conhecimento que servirá de sustentação ao processo de desenvolvimento de sua aprendizagem.

\section{Referências bibliográficas}

ALEKSANDROV, Aleksandr Danilovich et al. La matemática, su contenido, métodos y significado. Madrid: Alianza Editorial, 1985.

ALSINA, Claudia; BURGUÉS, Carme; FORTUNY, Josep Maria. Invitación a la didáctica de geometria. Madri: Síntesis, 1988.

ANGELI, Angela Maria Alves; NOGUEIRA, Clélia Maria Ignatius. A resolução de problemas como um caminho para o ensino e aprendizagem de geometria espacial, $2007 . \quad$ Disponível em: $<$ http://www.diaadiaeducacao.pr.gov.br/portals/pde/arquivos/945-4.pdf>. Acesso em: 16 ago 2013.

BALDISSERA, Altair. A geometria trabalhada a partir da construção de figuras e sólidos geométricos, 2007. Disponível em: $<$ www.gestaoescolar.diaadia.pr.gov.br/arquivos/File/producoes_pde/artigo_altai r_baldissera.pdf>. Acesso em: 01 ago 2013.

BOYER, Carl. B. História da matemática. $2^{\mathrm{a}} \mathrm{ed}$. São Paulo: Edgard Blücher, 1996.

BRASIL. Secretaria de Educação Fundamental. Parâmetros Curriculares Nacionais: apresentação dos temas transversais, ética. Brasília: MEC/SEF, 1997.

Ministério da Educação. Conselho Nacional de Educação. Câmera de Educação Básica. Orientações curriculares para o ensino médio. Brasília: MEC; SEB, 2006.

COSTA, Maria Aparecida; LIMA, Sônia Regina dos Reis. Ensino de prismas: uma análise a partir do livro didático. 2010. Monografia (Graduação em Licenciatura em Matemática) - Universidade Federal de Alfenas. Alfenas, 2010. Disponível em: <http://www.unifalmg.edu.br/matematica/files/file/estudo\%20de\%20prismas.pdf>. Acesso em: 16 mai 2016.

DANTE, Luiz Roberto. Formulação e resolução de problemas de matemática: Teoria e Prática. São Paulo: Ática, 2009.

DIAS, Lindomar Porpino; FERREIRA, Edna Cristina. Geometria: vivenciar e sentir sua presença no espaço onde vivemos. In. ENCONTRO PARAIBANO DE EDUCAÇÃO MATEMÁTICA, 8., Campina Grande, 27 a 29 de novembro, 2014. Anais... v.1, n.2, p.1-8, 2014. Disponível em: <http://www.editorarealize.com.br/revistas/epbem/normas.php>. Acesso em: 16 mai 2016.

ENGELS, F. Sobre o papel do trabalho na transformação do macaco em homem. In: MARX, K.; ENGELS, F. Textos. São Paulo: Edições Sociais, 1975. V.1.

EVES, Howard. An introduction to the history of mathematics. New York: Holt Rinehart and Winston, 1969. 
FREUDENTHAL, Hans. Mathematics as an educational trask. Dordrecht: Reidel, 1973.

GERDES, Paulus. Sobre o despertar do pensamento geométrico. Curitiba: UFPR, 1992.

GIL, Antonio Carlos. Como elaborar projetos de pesquisa. 5ed. São Paulo: Atlas, 2010.

HOFFER, Alan. Geometry is more than proof. Mathematics Teacher, v. 74, n. 1, p. 11-18, Jan.1981.

KALEFF, Ana Maria et al. Desenvolvimento do pensamento geométrico: modelo de Van Hiele. Bolema, v.10, p. 21-30, 1994.

; REI, Dulce Monteiro. Varetas, canudos, arestas e... sólidos geométricos. Revista do Professor de Matemática - RPM, n.28, p.122126, $1995 . \quad$ Disponível em: $<$ http://www.uff.br/leg/publicacoes/01_15_Varetas_Canudos_Arestas_1995.pdf >. Acesso em: 16 mai 2016.

KALEFF, A. M. M. R. Do fazer concreto ao desenho em geometria: ações e atividades desenvolvidas no laboratório de ensino de geometria da Universidade Federal Fluminense. In: LORENZATO, Sérgio. Laboratório de ensino de matemática na formação de professores. Campinas: Autores Associados, 2006. p. 113-134.

KRUTETSKY, Vadim Andreyevich. The psychology of mathematical abilities in schoolchildren. Chicago: University of Chicago Press, 1976.

LORENZATO, S. Laboratório de ensino de matemática e materiais didáticos manipuláveis. In: Laboratório de ensino de matemática na formação de professores. Campinas: Autores Associados, 2006. p. 3-38.

NASSER, Lílian. A construção do pensamento geométrico. In. ENCONTRO NACIONAL DE EDUCAÇÃO MATEMÁTICA, 6., São Leopoldo, 21 a 24 de julho de 1998. Anais... São Leopoldo: Unisinos, 1998. p. 71-74

OLIVEIRA, Ludmila Tamega Ferreira de. Habilidades espaciais subjacentes às atividades de discriminação e composição de figuras planas. 1998. Dissertação (Mestrado em Educação) - Universidade Estadual Paulista, São Paulo, 1998.

OLIVEIRA, Marta Kohl de. Aprendizado e processo de desenvolvimento: um processo sócio-histórico. São Paulo: Scipione, 1997.

PASSOS, C. L. B. Materiais manipuláveis como recursos didáticos na formação de professores de matemática. In: LORENZATO, Sérgio. Laboratório de ensino de matemática na formação de professores. Campinas: Autores Associados, 2006. p. 77-92.

PAVANELLO, Regina Maria. Geometria: atuação de professores e aprendizagem nas séries iniciais. In: SIMPÓSIO BRASILEIRO DE PSICOLOGIA DA EDUCAÇÃO MATEMÁTICA, 1., março de 2001. Anais... Curitiba: Editora da Universidade do Tuiuti do Paraná, 2001. p. 172-183.

PIRES, Célia Maria Caroline. Currículos de matemática: da organização linear à ideia de rede. São Paulo: FTD, 2000. 
PIROLA, Nelson Antonio. Um estudo sobre a formação de conceitos de triângulos e quadriláteros em alunos da quinta série do primeiro grau. 1995. Dissertação (Mestrado em Educação) - Faculdade de Educação, Unicamp, Campinas, 1995.

PONTE, João Pedro et al. Investigações geométricas. In: Investigações matemáticas na sala de aula. Belo Horizonte: Autêntica, 2003.

SANTOS, Maria Lucivânia Souza dos et al. Sólidos geométricos: relato de uma atividade com o uso de canudos e barbante. ENCONTRO NACIONAL DE EDUCAÇÃO MATEMÁTICA, 11., Curitiba, 18 a 21 de julho 2013, Anais... Curitiba: Sociedade Brasileira de Educação Matemática; Real Paraná, 2013. p. $1-9$. Disponível em: <http://sbem.web1471.kinghost.net/anais/XIENEM/pdf/2389_1379_ID.pdf>. Acesso em: 16 mai 2016.

SEVERINO, Antônio Joaquim. Metodologia do trabalho científico. São Paulo: Cortez, 2008.

TEIXEIRA, Jerônimo. A matemática que você não sabia que sabia. In: Revista Veja, São Paulo, n. 2.100, p. 128-130, 18 de fevereiro de 2009. Disponível em: <http://veja.abril.com.br/180209/p_128.shtml>. Acesso em: 10 set 2013.

THIOLLENT, Michel. Metodologia da pesquisa-ação. São Paulo: Cortez, 1985.

VIANA, Odaléa Aparecida. O conhecimento geométrico de alunos do Cefam sobre figuras espaciais: um estudo das habilidades e dos níveis de conceitos. São Paulo, 2000. Dissertação (Mestrado em Educação) - Universidade Estadual de Campinas. Campinas, 2000. 